\title{
Reduced-Pressure Boiling Extraction of Oleuropein Coupled with Ultrasonication from Olive Leaves (Olea europaea L.)
}

\author{
Pu-jun Xie, ${ }^{1,2,3,4,5}$ Li-xin Huang, ${ }^{1,2,3,4,5}$ Cai-hong Zhang, ${ }^{1,2,3,4,5}$ \\ Feng You, ${ }^{1,2,3,4}$ Cheng-zhang Wang, ${ }^{1,2,3,4,5}$ and Hao Zhou ${ }^{1,2,3,4,5}$ \\ ${ }^{1}$ Institute of Chemical Industry of Forest Products, CAF, Nanjing, Jiangsu 210042, China \\ ${ }^{2}$ National Engineering Laboratory for Biomass Chemical Utilization, Nanjing, Jiangsu 210042, China \\ ${ }^{3}$ Key and Open Laboratory on Forest Chemical Engineering, SFA, Nanjing, Jiangsu 210042, China \\ ${ }^{4}$ Key Laboratory of Biomass Energy and Material, Nanjing, Jiangsu 210042, China \\ ${ }^{5}$ Institute of New Technology of Forestry, CAF, Beijing 100091, China
}

Correspondence should be addressed to Li-xin Huang; 1_x_huang@163.com

Received 28 September 2014; Accepted 15 December 2014

Academic Editor: Xinfeng Xie

Copyright (C) $2015 \mathrm{Pu}$-jun Xie et al. This is an open access article distributed under the Creative Commons Attribution License, which permits unrestricted use, distribution, and reproduction in any medium, provided the original work is properly cited.

\begin{abstract}
Oleuropein was extracted from Frantoio olive leaves using reduced-pressure boiling extraction coupled with ultrasound-assist (URPE). Four important factors, extraction temperature, ultrasonic power, ethanol concentration, and the ratio of solid to liquid, were selected to carry out the response surface methodology (RSM) for seeking optimal conditions on high oleuropein extraction yield at different levels. Box-Behnken design was employed to investigate the effects of the four factors on it. The results showed that the ratio of solid to liquid was the most significant factor of all on oleuropein yield. The optimal operation conditions were obtained as follows: ethanol concentration $75 \%(\mathrm{v} / \mathrm{v})$, extraction temperature $53^{\circ} \mathrm{C}$, ultrasonic power $600 \mathrm{~W}$, and the ratio of solid to liquid 1:31. Under these optimal conditions, oleuropein extraction yield was 7.08\%, which was close to the predicted value $7.121 \%$. The scanning electron microscope (SEM) images of olive leaves after extraction were provided as well. It was seen that, compared with the untreated leaves, URPE could effectively break cells within the olive leaves.
\end{abstract}

\section{Introduction}

The olive trees (Olea europaea, Oleaceae) are widely distributed in China, Spain, Italy, Greece, and so forth [1]. The fruits of the trees could be squeezed into olive oil for edibility. It was considered as the main resource of dietary fat in Mediterranean countries and the most popular edible oil in the world [2]. However, full advantages of the leaves from the olive trees were not taken in the oil extraction process from olive fruit in most of oil mills. Olive leaves were burned or directly thrown away from the mills as environmentally detrimental waste products. In fact, it was discovered that olive leaves could be used as a folk remedy to treat fever and other diseases, such as malaria [3]. Beside olive oil, recent studies showed that many bioactive components such as oleuropein, hydroxytyrosol, verbascoside, rutin, and olive biophenols (OBPs), were found in oil leaves [4]. For
OBPs indicated a few of pharmacology properties for healthy benefits, that is, antioxidant [5-10], anti-inflammatory [11], antimicrobial [12-16], antitumor [17], anticancer [18], protection of cardiovascular disease $[9,19]$, and antidiabetics [20]. Nowadays, bioactive components, that is, oleuropein, have also been seen in cosmetics and pharmaceutics field. The chemical structure of oleuropein was shown in Figure 1 $[21,22]$. Moreover, it was observed that oleuropein content in olive leaves was greater than that in olive oil, and also the highest of all the different parts of the same olive tree, that is, olive fruit, bud and bark [23]. Therefore, it was very important for the researcher to find a highly effective and timely extraction method with the low cost in the processing of olive leaves.

It is known that, in the plant extraction field, conventional solvent extraction (CSE) was at a disadvantage of being time consuming, with a low extraction yield [24]. Ultrasonication 


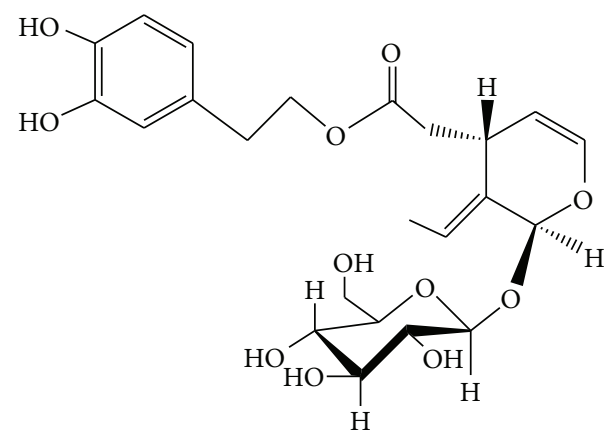

FIGURE 1: Chemical structure of oleuropein.

assisted extraction (UAE) could significantly improve the process due to oscillating and acoustic cavitation [25-27]. Additionally, reduced-pressure boiling extraction (RBE) was regarded as a relatively new extraction method, with process advantages of relatively low temperature requirements and high extraction effectiveness. Therefore, a combination of $\mathrm{RBE}$ and UAE (ultrasound-assisted extraction) was coupled for the extraction of oleuropein. To the best of our knowledge, ultrasound-assisted boiling extraction at reduced pressures (URPE) is being proposed for the first time and has not been investigated in the extraction of oleuropein from olive leaves.

In this paper, four important parameters, solvent, temperature, power, and the ratio of solid to liquid, were selected for optimization using response surface methodology (RSM) on the basis of a Box-Behnken design. In addition, visual evidence of the disruption of the cell way by URPE was provided by SEM images obtained by a scanning electron microscope.

\section{Materials and Methods}

2.1. Materials. Olive leaves (Frantoio) were purchased from Wudu County, Gansu, China, and dried in their natural condition without sunlight. They were milled (40-60 mesh) by high-speed drug crusher and stored in the dry and dark location at room temperature. All chemical reagents were purchased by Nanjing Chemical Reagents Co., Ltd., in China. A $1200 \mathrm{~W}, 20 \mathrm{kHz}$ ultrasonic generator (model FS-1200N, Shanghai Sonxi Co., Ltd., China) assembled with a probe transducer and a flat tip of $13.0 \mathrm{~mm}$ was used in the URPE experiments.

The HPLC equipment of Shimadzu Prominence LC-20A (Japan) was purchased from Shanghai Shimadzu Co., Ltd., in China. The HPLC system included a LC-20AT Solvent Delivery Unit, LC-20AT pump, 0-10 mL/min, a SPD-20A UV-VIS Detector, CBM-20Alite System Controller, LCsolution Single, Ver1.24 Workstation, and a 7725i Manual Sample Injector (Position Sensing Switch Incorporated) with a $20 \mu \mathrm{L}$ sample loop, Hamilton $702 \mathrm{SNR}(100 \mu \mathrm{L})$. SEM was used to view surface structure of samples (model S-3400N, Hitachi High Technologies Corporation, Japan).

\subsection{Methods}

2.2.1. Reduced-Pressure Boiling Extraction Oleuropein Coupled with Ultrasound-Assist. In URPE experiments, a standard ultrasonic probe with a flat tip of $13.0 \mathrm{~mm}$ in diameter was directly inserted into the mixture of olive leaves powder and extraction solvent and used as an ultrasonic source. The distance from flat top to flask bottom was controlled to about $3-5 \mathrm{~mm}$. A small fraction of artificial zeolite was put into a three-mouth flask with the samples and solvent. The specimens were boiled and irradiated under a vacuum degree at $75 \mathrm{kPa}$ and continuous ultrasonic waves for $3 \mathrm{~min}$ at a frequency of $20 \mathrm{kHz}$ with different levels (0-1200 W) of output power. Meanwhile, the temperature was varied by the experiment and was controlled within $\pm 1^{\circ} \mathrm{C}$. The treatment of the extract on oleuropein content was detected by HPLC.

\subsubsection{Extraction Yield Equation. Consider}

$$
\text { Yield }(\%)=\frac{W_{o}}{W_{t}} \times 100 \% \text {, }
$$

where $W_{o}$ is the content of oleuropein obtained from one extraction trial and $W_{t}$ is the weight of the total raw mass of olive leaves.

2.2.3. HPLC Analysis. The HPLC conditions were set on the basis of Xie's method for the determination of oleuropein [28]. Isocratic elution was implemented with methanol-water solution of $40: 60(\mathrm{v} / \mathrm{v})$ at a flow rate of $1 \mathrm{~mL} / \mathrm{min}$ and the runs could be achieved in $15 \mathrm{~min}$ under $232 \mathrm{~nm}$ detection. The retention time for oleuropein was about $11.5 \mathrm{~min}$. The method was precise, sensitive, and reproducible. Calibration for oleuropein was determined using the range from 1.06 to $10.6 \mu \mathrm{g}$ in six intervals; and the equation developed was linear and could be expressed by the following formula:

$$
Y=163365+1305700 X \quad\left(R^{2}=0.9992\right),
$$

where $X$ is the amount of standard used in calibration experiments and $Y$ is the relevant peak area in HPLC chromatographs. $R^{2}$ is very close to 1 , which means that there is a linear relationship between $Y$ and $X$, and the equation is adequate for quantitative analysis.

2.2.4. SEM Imaging. Samples particles treated by URBE were placed into a silicon wafer special in SEM equipment and subsequently analyzed with the microscope. The samples were first sputtered and then coated with a thin layer of conductive gold at a thickness of 50-100 nm. The shape and surface characteristics of the samples were observed and digitally recorded.

2.2.5. Trials of RSM. Optimization trials of extracting oleuropein from olive leaves were carried out using RSM, which is used as a method of optimization incorporating interaction effect between factors. For this purpose, a four-factor and three-level Box-Behnken design consisting of 29 experimental runs was employed including 5 center point replicates [29]. Four independent variables of the design were temperature $\left(X_{1},{ }^{\circ} \mathrm{C}\right)$, ultrasonic power $\left(X_{2}, \mathrm{~W}\right)$, ethanol concentration $\left(X_{3}, \%(\mathrm{v} / \mathrm{v}\right.$, ethanol/water $\left.)\right)$, and the ratio of solid to liquid $\left(X_{4}, \mathrm{~g} / \mathrm{mL}\right)$, and the response variable was the oleuropein extraction yield. In addition, the levels of the select factors 
TABLE 1: Design of factors and levels coded table.

\begin{tabular}{|c|c|c|c|c|c|}
\hline \multirow{2}{*}{ Independent variables } & \multirow{2}{*}{ Units } & \multirow{2}{*}{ Symbol } & \multicolumn{3}{|c|}{ Coded levels } \\
\hline & & & -1 & 0 & 1 \\
\hline Temperature & ${ }^{\circ} \mathrm{C}$ & $X_{1}$ & 40 & 50 & 60 \\
\hline Ultrasonic power & W & $X_{2}$ & 480 & 600 & 720 \\
\hline Ethanol concentration & $\%(\mathrm{v} / \mathrm{v})$ & $X_{3}$ & 65 & 75 & 85 \\
\hline Ratio of solid to liquid & $\mathrm{g} / \mathrm{mL}$ & $X_{4}$ & $1: 20$ & $1: 30$ & $1: 40$ \\
\hline
\end{tabular}

TABLe 2: Design and results of the RSM.

\begin{tabular}{|c|c|c|c|c|c|}
\hline Number & $\begin{array}{c}X_{1} \\
\text { Extraction } \\
\text { temperature }\end{array}$ & $\begin{array}{c}X_{2} \\
\text { Ultrasonic } \\
\text { power }\end{array}$ & $\begin{array}{c}X_{3} \\
\text { Ethanol } \\
\text { concentration }\end{array}$ & $\begin{array}{c}X_{4} \\
\text { Ratio of solid to } \\
\text { liquid } \\
\end{array}$ & Yield/\% \\
\hline 1 & -1 & -1 & 0 & 0 & 6.71 \\
\hline 2 & 1 & -1 & 0 & 0 & 6.77 \\
\hline 3 & -1 & 1 & 0 & 0 & 6.64 \\
\hline 4 & 1 & 1 & 0 & 0 & 6.79 \\
\hline 5 & 0 & 0 & -1 & -1 & 6.03 \\
\hline 6 & 0 & 0 & 1 & -1 & 5.95 \\
\hline 7 & 0 & 0 & -1 & 1 & 6.46 \\
\hline 8 & 0 & 0 & 1 & 1 & 5.93 \\
\hline 9 & -1 & 0 & 0 & -1 & 6.29 \\
\hline 10 & 1 & 0 & 0 & -1 & 6.39 \\
\hline 11 & -1 & 0 & 0 & 1 & 6.55 \\
\hline 12 & 1 & 0 & 0 & 1 & 6.68 \\
\hline 13 & 0 & -1 & -1 & 0 & 6.65 \\
\hline 14 & 0 & 1 & -1 & 0 & 6.81 \\
\hline 15 & 0 & -1 & 1 & 0 & 6.59 \\
\hline 16 & 0 & 1 & 1 & 0 & 6.63 \\
\hline 17 & -1 & 0 & -1 & 0 & 6.61 \\
\hline 18 & 1 & 0 & -1 & 0 & 6.59 \\
\hline 19 & -1 & 0 & 1 & 0 & 6.88 \\
\hline 20 & 1 & 0 & 1 & 0 & 6.93 \\
\hline 21 & 0 & -1 & 0 & -1 & 6.01 \\
\hline 22 & 0 & 1 & 0 & -1 & 5.91 \\
\hline 23 & 0 & -1 & 0 & 1 & 6.59 \\
\hline 24 & 0 & 1 & 0 & 1 & 6.39 \\
\hline 25 & 0 & 0 & 0 & 0 & 7.09 \\
\hline 26 & 0 & 0 & 0 & 0 & 7.13 \\
\hline 27 & 0 & 0 & 0 & 0 & 7.22 \\
\hline 28 & 0 & 0 & 0 & 0 & 6.99 \\
\hline 29 & 0 & 0 & 0 & 0 & 7.08 \\
\hline
\end{tabular}

and the coding results were shown in Table 1 . The design arrangement and the experimental results of the optimization design were displayed in Table 2. A second-order polynomial equation was used to fit the experimental data given in Table 2. The generalized model proposed for the response was given in the following equation:

$$
\begin{aligned}
Y_{i}= & \beta_{0}+\beta_{1} X_{1}+\beta_{2} X_{2}+\beta_{3} X_{3}+\beta_{4} X_{4} \\
& +\beta_{11} X_{1}^{2}+\beta_{22} X_{2}^{2}+\beta_{33} X_{3}^{2}+\beta_{44} X_{4}^{2}
\end{aligned}
$$

$$
\begin{aligned}
& +\beta_{12} X_{1} X_{2}+\beta_{13} X_{1} X_{3}+\beta_{14} X_{1} X_{4} \\
& +\beta_{23} X_{2} X_{3}+\beta_{24} X_{2} X_{4}+\beta_{34} X_{3} X_{4}
\end{aligned}
$$

where $Y_{i}$ is considered as predicted response value, $\beta_{0}$ is the value of fitting response at the center point of the design, $\beta_{i}$ 's are the linear coefficients, $\beta_{i}{ }^{2}$ 's are the quadratic coefficients, and $\beta_{i j}$ 's are the interaction coefficients, respectively. The 
TABLE 3: The variance analysis and significance test table of regression coefficient of response surface design.

\begin{tabular}{|c|c|c|c|c|c|}
\hline Source of variation & Degree of freedom & Sum of squares & Mean squares & $F$-test & $P$ value \\
\hline$X_{1}$ & 1 & 0.018 & 0.018 & 0.60 & 0.45 \\
\hline$X_{2}$ & 1 & 0.0019 & 0.0019 & 0.062 & 0.81 \\
\hline$X_{3}$ & 1 & 0.0048 & 0.0048 & 0.16 & 0.70 \\
\hline$X_{4}$ & 1 & 0.34 & 0.34 & 11.16 & $0.0049^{* *}$ \\
\hline$X_{1} X_{2}$ & 1 & 0.0020 & 0.0020 & 0.066 & 0.80 \\
\hline$X_{1} X_{3}$ & 1 & 0.0012 & 0.0012 & 0.040 & 0.84 \\
\hline$X_{1} X_{4}$ & 1 & 0.0002 & 0.0002 & 0.0074 & 0.93 \\
\hline$X_{2} X_{3}$ & 1 & 0.0036 & 0.0036 & 0.12 & 0.74 \\
\hline$X_{2} X_{4}$ & 1 & 0.0025 & 0.0025 & 0.082 & 0.78 \\
\hline$X_{3} X_{4}$ & 1 & 0.051 & 0.051 & 1.66 & 0.22 \\
\hline$X_{1}^{2}$ & 1 & 0.026 & 0.026 & 0.85 & 0.37 \\
\hline$X_{2}^{2}$ & 1 & 0.34 & 0.34 & 11.32 & $0.0046^{* *}$ \\
\hline$X_{3}{ }^{2}$ & 1 & 0.52 & 0.52 & 17.21 & $0.0010^{* *}$ \\
\hline$X_{4}^{2}$ & 1 & 2.69 & 2.69 & 88.36 & $<0.0001^{* *}$ \\
\hline Model & 14 & 3.41 & 0.24 & 7.99 & $0.0002^{* *}$ \\
\hline Residual & 14 & 0.43 & 0.03 & & \\
\hline Lack of fit significant & 10 & 0.40 & 5.72 & 0.053 & 0.0537 \\
\hline Pure error & 4 & 0.028 & 0.0070 & & \\
\hline Corrected total & 28 & 3.83 & & & \\
\hline
\end{tabular}

** Significant at 0.01 .

computational software for this study was Design-Expert, version: 8.0.5.0, by Stat-Ease, Inc.

2.2.6. Verification of the Optimal Conditions. To check the validity of the model, the predicted value of the oleuropein yield was compared with the practical value under the optimal conditions, obtained by the second-order polynomial model of RSM.

\section{Results and Discussion}

3.1. Design and Results of RSM Experiments. Four important factors, temperature, ultrasound power, ethanol concentration, and the ratio of solid to liquid, as well as the ranges of these four factors were selected to take the experiments of RSM to simulate a mathematic relationship about the four factors and oleuropein yield. The different variances of regression and significance were shown in Table 3. As it was shown in Table $3, X_{4}, X_{2}{ }^{2}, X_{3}{ }^{2}$, and $X_{4}{ }^{2}$ were significant at level $P_{0.01}$, and the $F_{0.05}$ value for lack of fit indicated that the lack of fit was not significant. The model itself was significant at level $P_{0.01}$, which implied that the model was dependable. Thus, the fitted model was appropriate for describing the response surface. According to Table 3, a second-order polynomial equation for extraction yield of oleuropein was obtained for the factors coded as shown in the following equation:

$$
\begin{gathered}
Y=7.10+0.039 \quad X_{1}-0.012 \quad X_{2}-0.020 \\
X_{3}+0.17 \quad X_{4}+0.022 \quad X_{1} X_{2}+0.018 X_{1} X_{3}+0.0075 \\
X_{1} X_{4}-0.03 \quad X_{2} X_{3}-0.025 \quad X_{2} X_{4}-0.11
\end{gathered}
$$

$$
\begin{gathered}
X_{3} X_{4}-0.063 \quad X_{1}^{2}-0.23 \quad X_{2}^{2}-0.28 \\
X_{3}^{2}-0.64 \quad X_{4}^{2} \\
\left(R^{2}=0.89\right)
\end{gathered}
$$

By means of $F$-test and $P$ value, as it was shown in Table 3, it was seen that the quadratic term of the ratio of solid to liquid $\left(X_{4}^{2}\right)$ had the most significant effect on the extraction yield of oleuropein, followed by the quadratic term of ethanol concentration $\left(X_{3}{ }^{2}\right)$, the quadratic term of ultrasonic power $\left(X_{2}^{2}\right)$, and the ratio of solid to liquid $\left(X_{4}\right)$.

3.2. Analysis of RSM Experiments. As it was shown in Figure 2, six group graphs from the four factors were depicted by three-dimensional plots in order to illustrate the RSM problem. Two factors changed, while the other two were kept constant at zero, also called the central point. Figure 2(a) showed that the interactive effect between temperature and ultrasonic power was not significant and extraction yield increased when the temperature increased for all ultrasonic powers, while this law was not the same as ultrasonic power for all the temperatures. Optimal ultrasonic power $600 \mathrm{~W}$ could be the best of extraction yield for all the temperatures. Figure 2(b) displayed the interactive effects of temperature and ethanol concentration, and they also were not significant. When temperature was constant, extraction yield obtained $7.1 \%$ when ethanol concentration was $75 \%$. The relationship of extraction temperature and the ratio of solid to liquid with extraction yield of oleuropein was shown in Figure 2(c). The results showed that extraction yield increased with the 


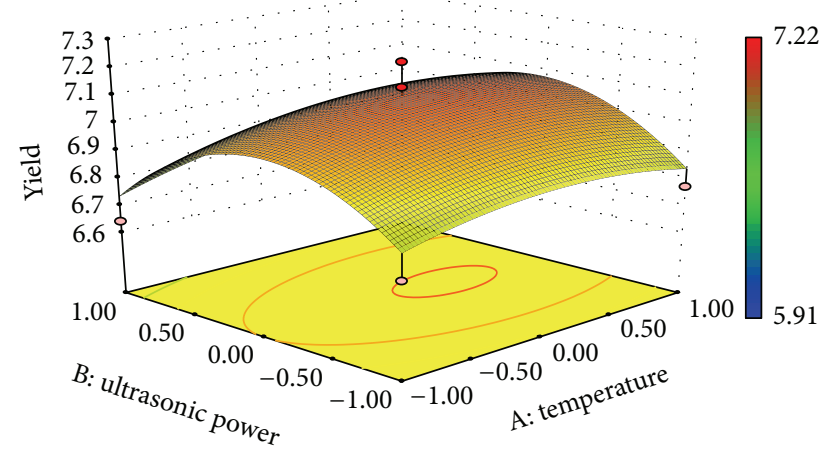

Design-Expert? software Factor coding: coded

Yield

$X_{1}=$ A: temperature

$X_{2}=$ B: ultrasonic power

Design points above predicted value C: ethanol concentration $=0.000$

O Design points below predicted value $\mathrm{D}$ : ratio of solid to liquid $=0.000$

(a) Response surface showing effect of ultrasonic power and temperature

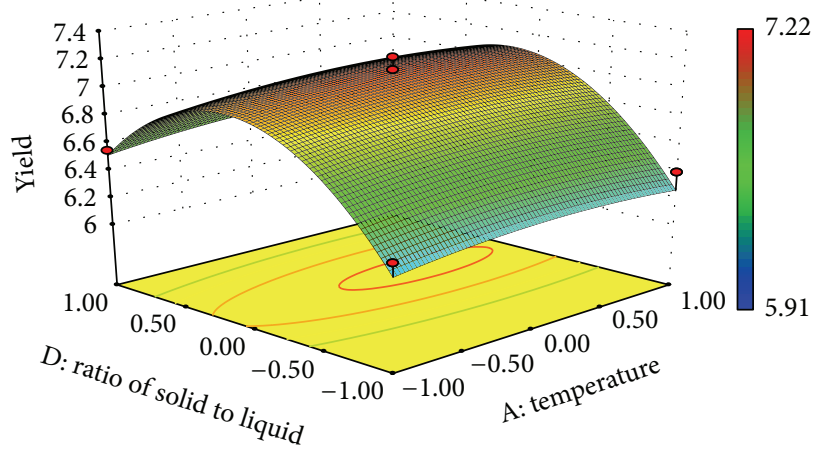

Design-Expert? software

Factor coding: coded

Yield

$X_{1}=$ A: temperature

$X_{4}=$ D: ratio of solid to liquid

Coded factors

O Design points above predicted value $\quad B$ : ultrasonic power $=0.000$

O Design points below predicted value $\mathrm{C}$ : ethanol concentration $=0.000$

(c) Response surface showing effect of the ratio of solid to liquid and temperature

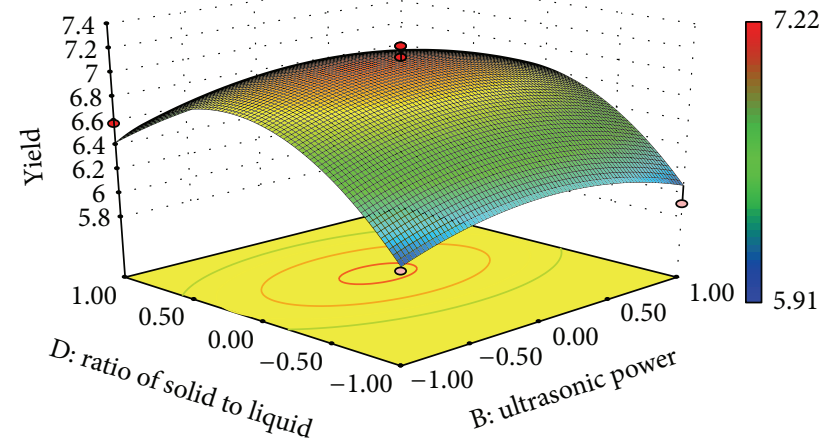

Design-Expert? software

Factor coding: coded

Yield

$X_{2}=$ B: ultrasonic power

$X_{4}=$ D: ratio of solid to liquid

O Design points above predicted value A: temperature $=0.000$

Design points below predicted value C: ethanol concentration $=0.000$

(e) Response surface showing effect of ultrasonic power and ratio of solid to liquid

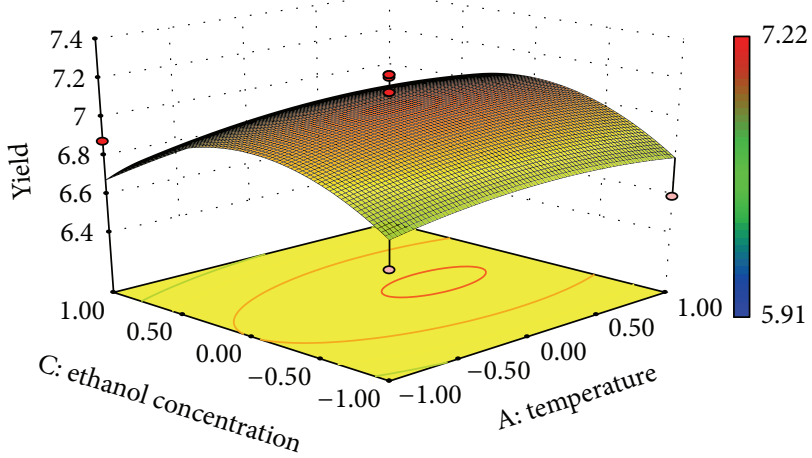

Design-Expert? software

Factor coding: coded

Yield

$X_{1}=$ A: temperature

Design points above predicted value $\quad$ B: ultrasonic power $=0.000$

O Design points below predicted value $\mathrm{D}$ : ratio of solid to liquid $=0.000$

(b) Response surface showing effect of ethanol concentration and temperature

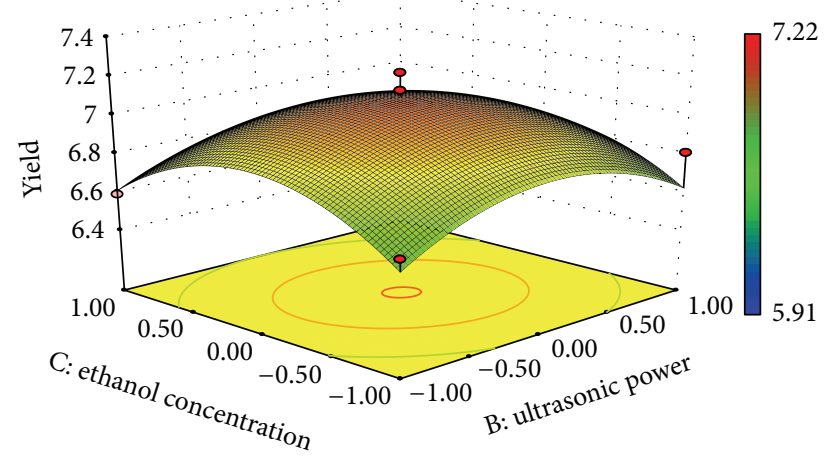

Design-Expert? software

Factor coding: coded

Yield

$X_{2}=$ B: ultrasonic power

O Design points above predicted value A: temperature $=0.000$

O Design points below predicted value $\mathrm{D}$ : ratio of solid to liquid $=0.000$

(d) Response surface showing effect of ethanol concentration and utrasonic power

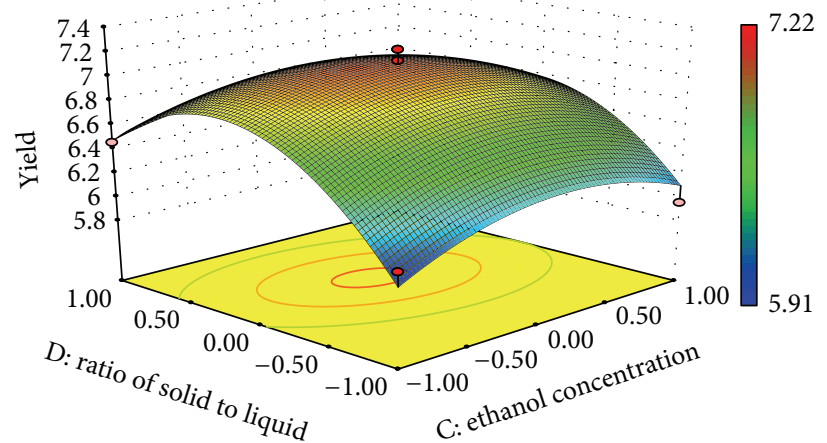

Design-Expert? software

Factor coding: coded

$X_{3}=$ C: ethanol concentration

Yield

$X_{4}=$ D: ratio of solid to liquid

Coded factors

- Design points above predicted value A: temperature $=0.000$

O Design points below predicted value $\quad$ B: ultrasonic power $=0.000$

(f) Response surface showing effect of ethanol concentration and ratio of solid to liquid

FIGURE 2: Response surface plot optimization of extraction yield between factors. 


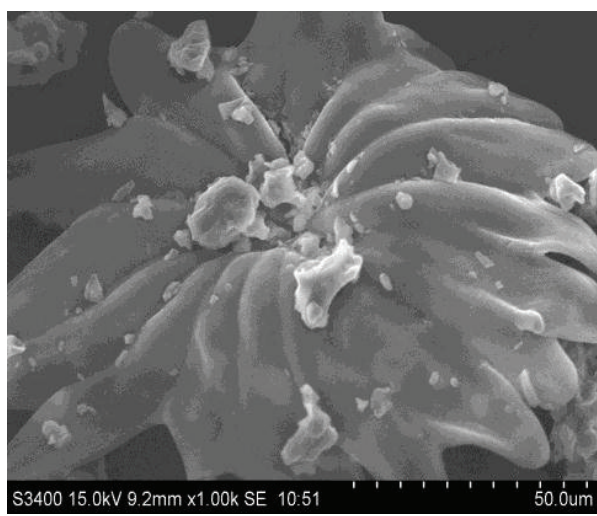

(a) Untreated samples

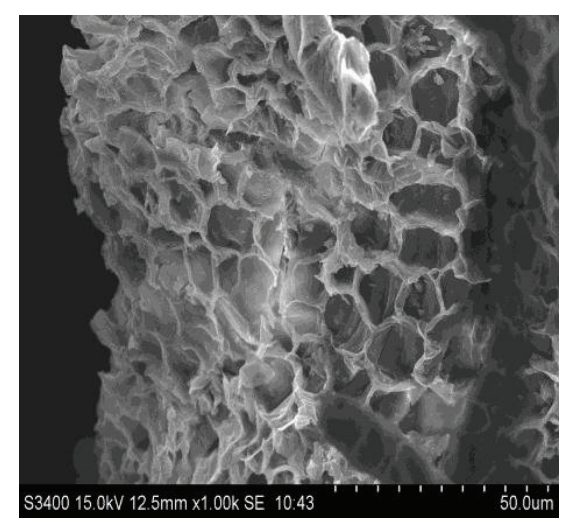

(b) Samples treated by URPE

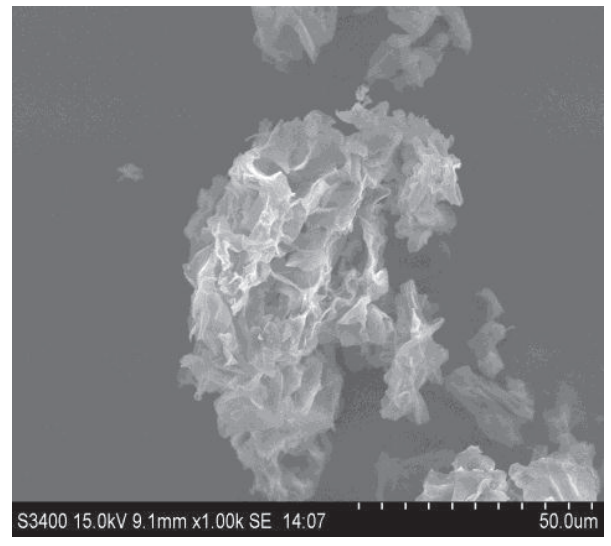

(c) Samples treated by RBE

FIGURE 3: Displaying samples after being treated by URPE and RBE, compared with untreated ones.

increasing of the ratio up to $1: 30$, followed by decrease afterwards. From the graph it is also determined that the factor of the ratio of solid to liquid had a profound effect on the extraction yield. The interactive relationship between ultrasonic power and ethanol concentration was displayed in Figure 2(d). As the graph showed, extraction yield improved with the increase of ethanol concentration, followed by a slight decrease. The same situation was found with the ultrasonic power. Thus, ultrasonic power $600 \mathrm{~W}$ and $75 \%$ of ethanol concentration were optimal conditions for the extraction. Figure 2(e) showed the interactive relationship between ultrasonic power and the ratio of solid to liquid. The extraction yield almost formed a linear relationship with ultrasonic power and was not significant, while the yield displayed a quadratic relationship with the ratio of solid to liquid and was extremely significant. The relationship of ethanol concentration and the ratio of solid to liquid was shown in Figure 2(f). The effect of the ratio of solid to liquid was also significant as mentioned above and the ethanol concentration had an important influence on the extraction yield. From the graph, the optimal conditions were $75 \%$ ethanol concentration and a 1:30 solid to liquid ratio, respectively.

According to the calculation of software Design-Expert version 8.0.5.0, optimal conditions of extraction were obtained when temperature was at $53.1^{\circ} \mathrm{C}$, ultrasonic power
$599.8 \mathrm{~W}$, ethanol concentration $74.5 \%$, and the ratio of solid to liquid 1:31.4. Considering the practical operation, the final optimal conditions were revised to temperature: $53^{\circ} \mathrm{C}$, ultrasonic power: $600 \mathrm{~W}$, ethanol concentration: $75 \%$, and the ratio of solid to liquid: $1: 31$.

3.3. Verification of the Results. Predicating optimal response values of the model for the suitability was tested by recommending the optimal conditions. The set of optimal conditions decided by RSM optimization method, together with the other two central points, extraction time $3 \mathrm{~min}$, and vacuum degree $75 \mathrm{Kpa}$, were tested experimentally compared with the predicted value of extraction yield and with these optimal conditions, the predicted value of extraction yield of oleuropein was $7.121 \%$, while the experimental value was $7.08 \%$ which was close to predicted value.

3.4. SEM of Olive Leaves after URPE. From the SEM, compared with Figure 3(a), the samples cell walls processed by URPE and RBE were broken, just as Figures 3(b) and 3(c) showed. The graphs obviously observed that the damage degree of the sample processed by URPE was stronger than that of RBE. One possible reason for the broken cell walls broken by URPE was that extraction solvent first infiltrated the cell wall and then produced boiling bubbles inside the cell when the outside conditions reached the boiling point of the 
solvent. The continuous bubbling caused a cracking of cell walls. Also, UAE could create this physical effect in the cell wall, when coupled with the other extraction methods, where the samples were broken by the ceaseless shock.

\section{Conclusions}

In this paper, four important factors (i.e., extraction temperature, ultrasonic power, ethanol concentration, and the ratio of solid to liquid) were selected to carry out experimental optimization using Box-Behnken design. Based on the Ftest analysis and $P$ value results of RSM, the quadratic term of the ratio of solid to liquid $\left(X_{4}^{2}\right)$ had the largest effect on oleuropein extraction yield. The optimization conditions were determined as follows: extraction temperature $53^{\circ} \mathrm{C}$, ultrasonic power $600 \mathrm{~W}$, ethanol concentration $75 \%$, and the ratio of solid to liquid $1: 31$. With these optimized conditions, the experimental value of oleuropein extraction yield (7.08\%) was very close to the predicted value of $7.121 \%$. A secondorder polynomial equation for extraction yield of oleuropein was obtained by expounding the following equation:

$$
\begin{gathered}
Y=7.10+0.039 \quad X_{1}-0.012 \quad X_{2}-0.020 \\
X_{3}+0.17 \quad X_{4}+0.022 \quad X_{1} X_{2}+0.018 \\
X_{1} X_{3}+0.0075 \quad X_{1} X_{4}-0.03 \quad X_{2} X_{3}-0.025 \\
X_{2} X_{4}-0.11 \quad X_{3} X_{4}-0.063 \quad X_{1}^{2}-0.23 \\
X_{2}^{2}-0.28 \quad X_{3}^{2}-0.64 \quad X_{4}^{2} \\
\left(R^{2}=0.89\right)
\end{gathered}
$$

which fits the data well. In addition, the SEM images have provided excellent visual evidence of the effectiveness of URPE. Consequently, it is determined to be a feasiable, efficient, and promising extraction technology for the extraction of bioactive ingredients from natural plants.

\section{Conflict of Interests}

The authors declare that there is no conflict of interests regarding the publication of this paper.

\section{Acknowledgment}

The authors acknowledge the financial support by funding project "948 items of introducing forestry special products using ultrasonic atomizing drying technology (2012-4-12)."

\section{References}

[1] T. Huang, "Olive fruit production in the world," World Agriculture, vol. 3, pp. 29-30, 1998 (Chinese).

[2] F. Kotti, E. Chiavaro, L. Cerretani, C. Barnaba, M. Gargouri, and A. Bendini, "Chemical and thermal characterization of Tunisian extra virgin olive oil from Chetoui and Chemlali cultivars and different geographical origin," European Food Research and Technology, vol. 228, no. 5, pp. 735-742, 2009.
[3] O. Benavente-García, J. Castillo, J. Lorente, A. Ortuño, and J. A. del Rio, "Antioxidant activity of phenolics extracted from Olea europaea L. leaves," Food Chemistry, vol. 68, no. 4, pp. 457-462, 2000.

[4] E. Altiok, D. Bayçin, O. Bayraktar, and S. Ülkü, "Isolation of polyphenols from the extracts of olive leaves (Olea europaea L.) by adsorption on silk fibroin," Separation and Purification Technology, vol. 62, no. 2, pp. 342-348, 2008.

[5] F. Visioli, S. Bellosta, and C. Galli, "Oleuropein, the bitter principle of olives, enhances nitric oxide production by mouse macrophages," Life Sciences, vol. 62, no. 6, pp. 541-546, 1998.

[6] F. Visioli and C. Galli, "Nikolaj Nikolajewitsch Anitschkow (1885-1964) established the cholesterol-fed rabbit as a model for atherosclerosis research," Atherosclerosis, vol. 135, no. 1, pp. 1-7, 1997.

[7] N. K. Andrikopoulos, S. Antonopoulou, and A. C. Kaliora, "Oleuropein inhibits LDL oxidation induced by cooking oil frying by-products and platelet aggregation induced by plateletactivating factor," Lebensmittel-Wissenschaft und-Technologie, vol. 35, no. 6, pp. 479-484, 2002.

[8] H. Jemai, M. Bouaziz, I. Feki, and S. Sayadi, "Hypolipidimic and antioxidant activities of oleuropein and its hydrolysis derivative-rich extracts from Chemlali olive leaves," ChemicoBiological Interactions, vol. 176, no. 2-3, pp. 88-98, 2008.

[9] K. A. Nikolaos, A. Smaragdi, and C. K. Andriana, "Oleuropein inhibits LDL oxidation induced by cooking oil frying byproducts and platelet aggregation induced by platelet-activating factor," LWT-Food Science and Technology, vol. 35, no. 6, pp. 479-484, 2002.

[10] H. Jemai, M. Bouaziz, I. Fki, A. El Feki, and S. Sayadi, "Hypolipidimic and antioxidant activities of oleuropein and its hydrolysis derivative-rich extracts from Chemlali olive leaves," Chemico-Biological Interactions, vol. 176, no. 2-3, pp. 88-98, 2008.

[11] I. Stupansa, M. Murrayb, A. Kirlicha, K. L. Tuck, and P. J. Hayball, "Inactivation of cytochrome P450 by the food-derived complex phenol oleuropein," Food and Chemical Toxicology, vol. 39, no. 11, pp. 1119-1124, 2001.

[12] F. Visioli, G. Bellomo, G. Montedoro, and C. Galli, "Low density lipoprotein oxidation is inhibited in vitro by olive oil constituents," Atherosclerosis, vol. 117, no. 1, pp. 25-32, 1995.

[13] S. Lee-Huang, L. Zhang, P. L. Huang, Y.-T. Chang, and P. L. Huang, "Anti-HIV activity of olive leaf extract (OLE) and modulation of host cell gene expression by HIV-1 infection and OLE treatment," Biochemical and Biophysical Research Communications, vol. 307, no. 4, pp. 1029-1037, 2003.

[14] E. D. Clercq, "Chemotherapeutic approaches to the treatment of the acquired immune deficiency syndrome (AIDS)," Journal of Medicinal Chemistry, vol. 29, no. 9, pp. 1561-1569, 1986.

[15] G. Q. Zhao, Z. F. Yin, and J. X. Dong, "Antiviral efficacy against hepatitis $B$ virus replication of oleuropein isolated from Jasminum officinale L. var. grandiflorum," Journal of Ethnopharmacology, vol. 125, no. 2, pp. 265-268, 2009.

[16] V. Micol, N. Caturla, L. Pérez-Fons, V. Más, L. Pérez, and A. Estepa, "The olive leaf extract exhibits antiviral activity against viral haemorrhagic septicaemia rhabdovirus (VHSV)," Antiviral Research, vol. 66, no. 2-3, pp. 129-136, 2005.

[17] H. K. Hamdi and R. Castellon, "Oleuropein, a non-toxic olive iridoid, is an anti-tumor agent and cytoskeleton disruptor," Biochemical and Biophysical Research Communications, vol. 334, no. 3, pp. 769-778, 2005. 
[18] J. Han, N. Tallrete, P. Yamada, and H. Isoda, "Anti-proliferative and apoptotic effects of oleuropein and hydroxytyrosol on human breast cancer MCF-7 cells," Cytotechnology, vol. 59, no. 1, pp. 45-53, 2009.

[19] I. Andreadou, M. Papaefthimiou, A. Zira et al., "Oleuropein restores the pathological metabolic pathways induced by doxorubicin's cardiotoxicity. An NMR based metabonomic study," Journal of Molecular and Cellular Cardiology, vol. 42, no. 6, supplement, pp. S168-S169, 2007.

[20] H. F. Al-Azzawie and M. S. S. Alhamdani, "Hypoglycemic and antioxidant effect of oleuropein in alloxan-diabetic rabbits," Life Sciences, vol. 78, no. 12, pp. 1371-1377, 2006.

[21] H. P. Fleming, W. M. Walter Jr., and J. L. Etchells, "Antimicrobial properties of oleuropein and products of its hydrolysis from green olives," Applied and Environmental Microbiology, vol. 26, no. 5, pp. 777-782, 1973.

[22] L. M. Panizzi, J. M. Scarpati, and E. G. Oriente, “ The constitution of oleuropein, a bitter glucoside of the olive with hypotensive action," Gazzetta Chimica Italiana, vol. 90, pp. 1449-1485, 1960.

[23] J. A. del Río, A. G. Báidez, J. M. Botía, and A. Ortuño, “Enhancement of phenolic compounds in olive plants (Olea europaea L.) and their influence on resistance against Phytophthora sp," Food Chemistry, vol. 83, no. 1, pp. 75-78, 2003.

[24] E. Q. Xia, X. X. Ai, S. Y. Zang, T. T. Guan, X. R. Xu, and H. B. $\mathrm{Li}$, "Ultrasound-assisted extraction of phillyrin from Forsythia suspensa," Ultrasonics Sonochemistry, vol. 18, no. 2, pp. 549-552, 2011.

[25] F. Chemat and M. K. Khan, "Applications of ultrasound in food technology: processing, preservation and extraction," Ultrasonics Sonochemistry, vol. 18, no. 4, pp. 813-835, 2011.

[26] N. Y. Yuhana, S. Ahmad, and A. R. Shamsul Bahri, "The effect of ultrasonic treatment on thermal stability of the cured epoxy/layered silicate nanocomposite," Advances in Materials Science and Engineering, vol. 2012, Article ID 789815, 5 pages, 2012.

[27] T. Jerman, P. Trebše, and B. M. Vodopivec, "Ultrasound-assisted solid liquid extraction (USLE) of olive fruit (Olea europaea) phenolic compounds," Food Chemistry, vol. 123, no. 1, pp. 175182, 2010.

[28] P. J. Xie, L. X. Huang, C. H. Zhang, F. You, C. Z. Wang, and H. Zhou, "Optimization of ultrasound-assisted extraction of oleuropein from Olea europaea L. leaf using response surface methodology," Natural Product Research and Development, vol. 24, no. 7, 2012, (Chinese).

[29] Z. X. Lin, H. M. Zhang, and J. P. Shi, "Characterization of ball milling pretreated corn stover and optimization enzymatic hydrolysis parameters," Journal of Biobased Materials and Bioenergy, vol. 7, no. 5, pp. 579-587, 2013. 

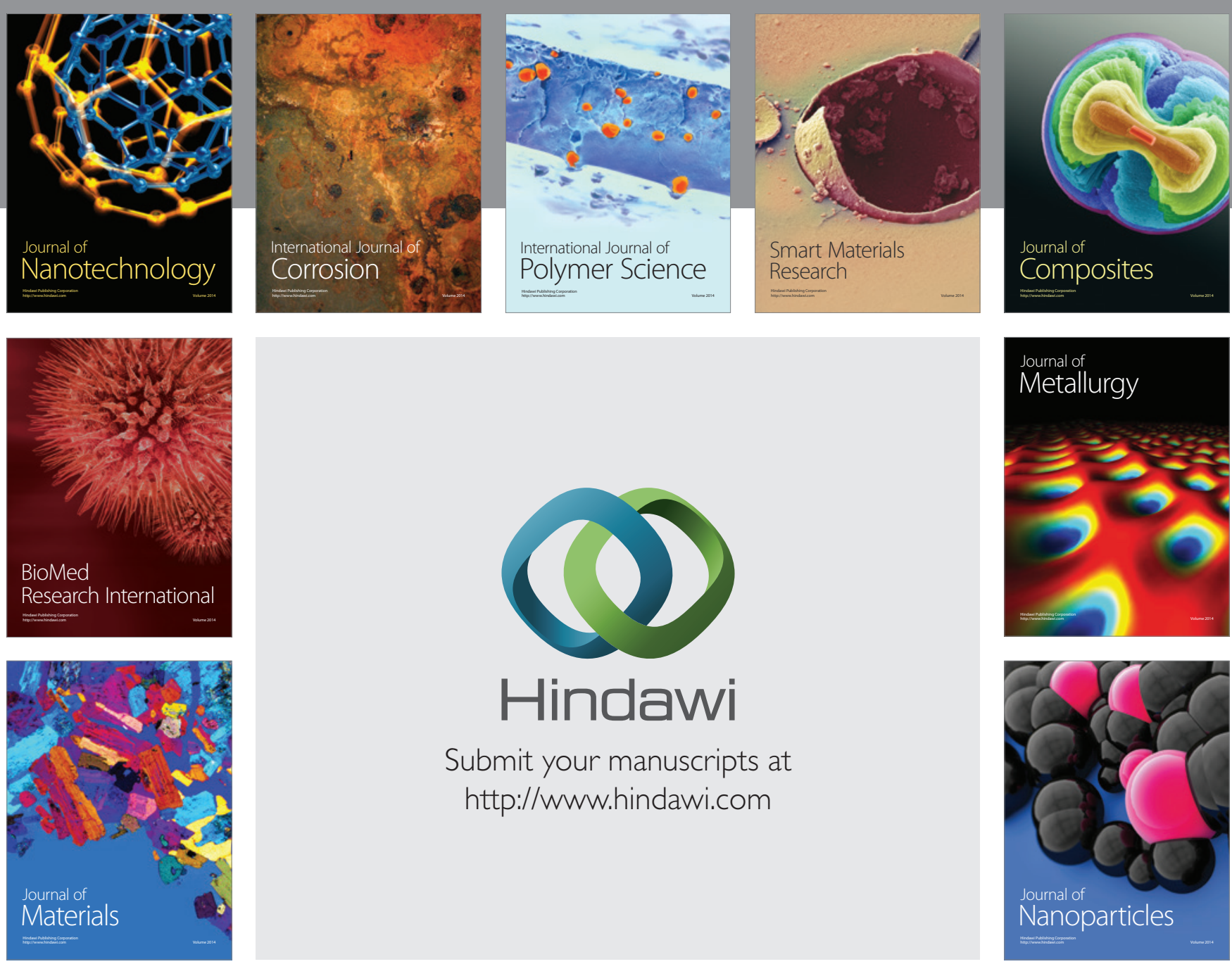

Submit your manuscripts at http://www.hindawi.com
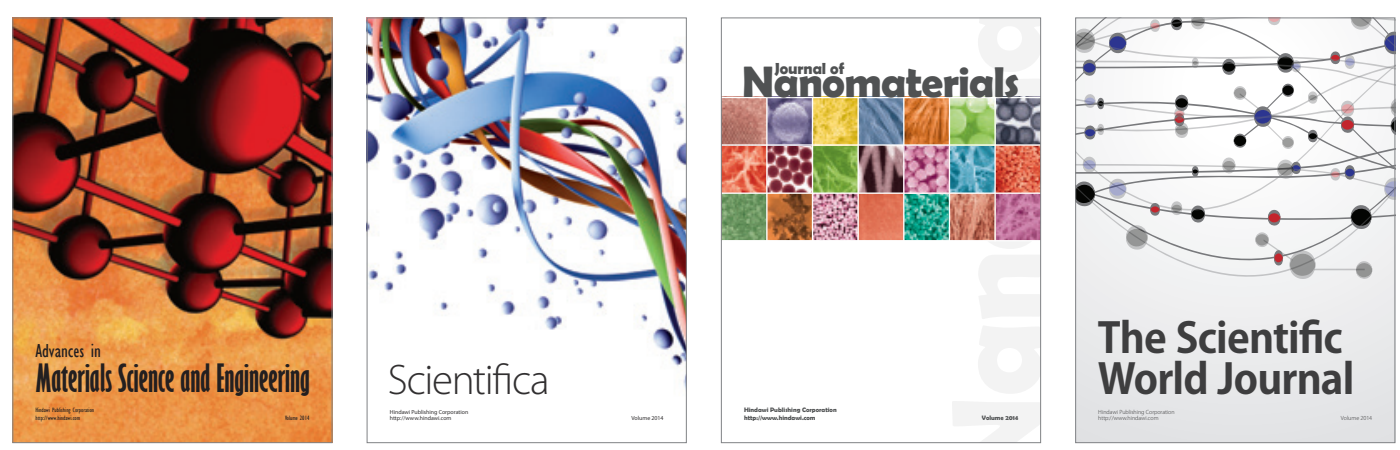

\section{The Scientific World Journal}
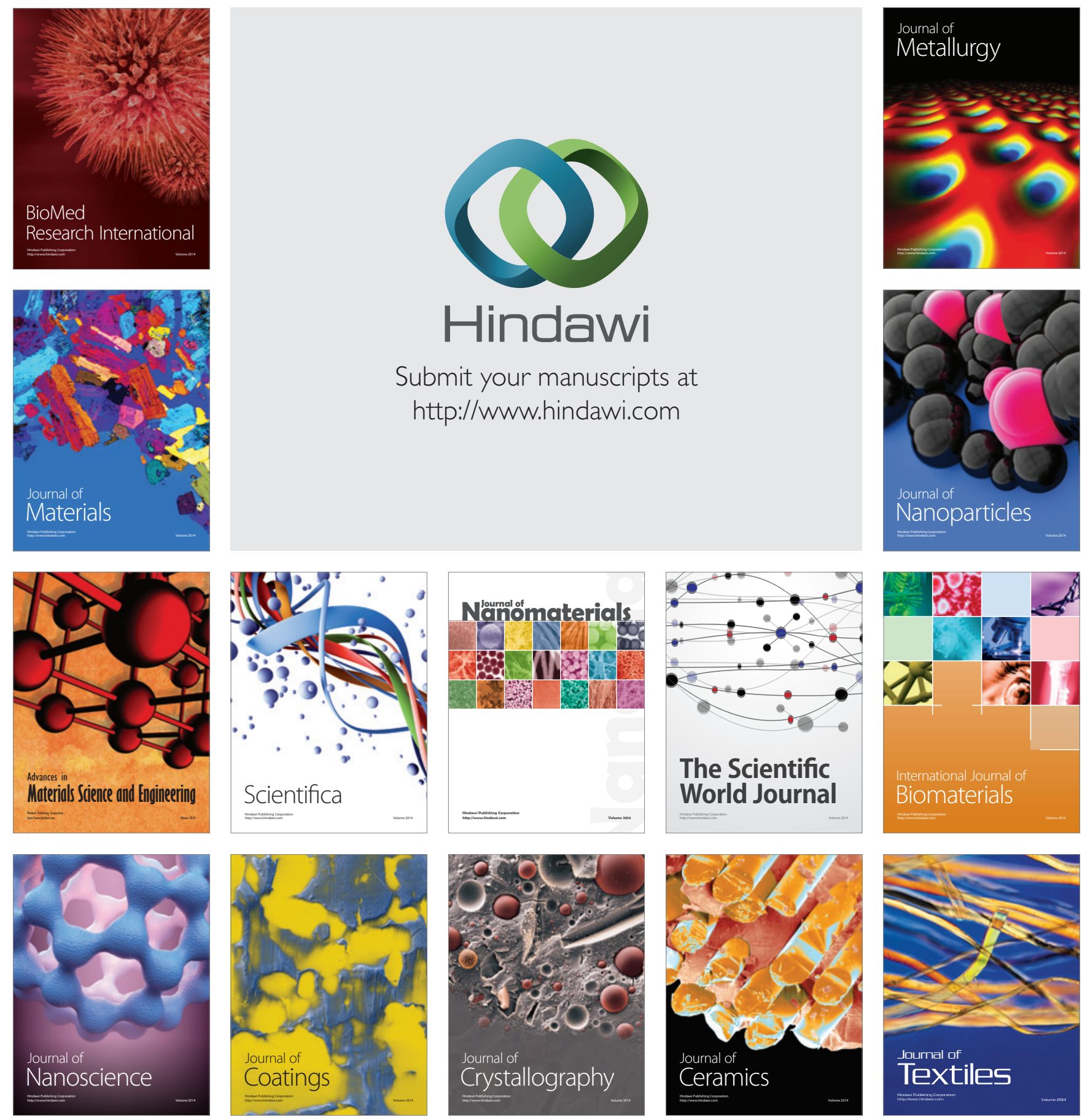